\title{
Effects of Five Weeks of Resistance Training and Relatively- Dosed Creatine Monohydrate Supplementation on Body Composition and Muscle Strength, and Whole-Body Creatine Metabolism in Resistance-Trained Males
}

\author{
Thomas L. Andre \\ Department of Health, Human Performance, and Recreation, Baylor University1312 South 5th Street, Waco, TX 76798, United States \\ E-mail: Thomas_Andre@baylor.edu \\ Joshua J. Gann \\ Department of Health, Human Performance, and Recreation, Baylor University, 1312 South 5th Street, Waco, TX 76798, United States \\ E-mail: Joshua_Gann@baylor.edu \\ Sarah K. McKinley-Barnard \\ Department of Health, Human Performance, and Recreation, Baylor University, 1312 South 5th Street, Waco, TX 76798, United States \\ E-mail: Sarah_McKinley@baylor.edu \\ Darryn S. Willoughby (Corresponding author) \\ Department of Health, Human Performance, and Recreation, Baylor University, 1312 South 5th Street, Waco, TX 76798, United States \\ E-mail: Darryn_Willoughby@baylor.edu \\ Received: 06-02-2016 \\ doi:10.7575/aiac.ijkss.v.4n.2p.27 \\ Accepted: 28-03-2016 \\ Published: 30-04-2016 \\ URL: http://dx.doi.org/10.7575/aiac.ijkss.v.4n.2p.27
}

The research received creatine and maltodextrose products generously donated by AST Sports Science; Golden, CO. The study was supported by a graduate student research grant from the Department of Health, Human Performance, and Recreation and the Exercise and Biochemical Nutrition Laboratory of Baylor University.

\begin{abstract}
Background: Creatine ( $\mathrm{Cr}$ ) supplementation has been established as an ergogenic aid in most individuals during anaerobic exercise. However, discrepancies exist in the data when using absolute dosing. Objective: The effects of five weeks of resistance training with relatively-dosed $\mathrm{Cr}$ followed by four weeks of resistance training after ceasing supplementation were determined. Methods: Resistance-trained men, $19(\mathrm{CR}=9, \mathrm{PL}=10)$, ingested Cr or placebo for five weeks with resistance training. Participants ingested $0.3 \mathrm{~g} / \mathrm{kg}$ lean body mass/day for one week, $0.075 \mathrm{~g} / \mathrm{kg}$ lean body mass/day for four weeks, with a four-week wash out. Five muscle samples, six blood samples, and nine urine samples were collected. Separate two-way ANOVAs for each criterion variable were used employing an alpha level of $\leq$ 0.05. Results: A group $x$ time interaction for increased total body mass for CR Day 1 and $64(p=0.03)$ and total lean mass for CR Day 1 and $64(\mathrm{p}=0.01)$. Group $\mathrm{x}$ time interactions occurred for $\mathrm{Cr}$ supplementation increasing serum $\mathrm{Cr}$ at Day 4,8 , and $22(\mathrm{p}=0.03)$, urinary $\mathrm{Cr}$ at Day $4(\mathrm{p}=0.01)$, and total muscle $\mathrm{Cr}$ at Day $8(\mathrm{p}<0.001), 22(\mathrm{p}=0.003)$, and $36(p<0.001)$. No significant differences occurred for serum $(p=0.14)$ or urine $(p=0.15)$ creatinine. Conclusion: Elevated levels of urinary $\mathrm{Cr}$ demonstrate dosing could be reduced.
\end{abstract}

Keywords: Urine, creatinine, resistance training, muscle strength, serum

\section{Introduction}

Creatine $(\mathrm{Cr})$ is a naturally-occurring amino acid derivative that is endogenously synthesized primarily in the liver from arginine, glycine, and methionine. It contributes to the generation of adenosine triphosphate (ATP), which is necessary for muscular contraction (Beasman et al.,1985). Cr supplementation during resistance training has demonstrated varying effects on muscle mass and strength (Lanhers et al., 2015). The increase of intramuscular Cr concentration following supplementation has demonstrated a considerable variability in humans, suggesting a potential responder effect (Greenhaff et al., 1994). A typical Cr supplementation protocol, [loading phase of $20 \mathrm{~g}$ of Cr per day (4 x 5 g) for 3-7 days, a maintenance phase of 4-5 g per day for four weeks, and a wash out phase of four weeks before the cycle is restarted] has been verified to significantly increase intramuscular $\mathrm{Cr}$ and phophorylcreatine stores (Cooper et al., 2012; Hultman et al., 1996; Lemon 2002). However, $\sim 160 \mathrm{mmol} / \mathrm{kg}$ dry mass appears to be the upper limit for total 
intramuscular $\mathrm{Cr}$ concentration, and additional $\mathrm{Cr}$ is excreted in the urine (Greenhaff et al., 1994).

Absolute doses are typically employed for $\mathrm{Cr}$ supplementation, but create a potential confounder because absolute doses elicit varying increases in serum and intramuscular $\mathrm{Cr}$ concentrations among individuals with different body masses. Hultman et al., (1996) suggested a relative loading dose of $0.3 \mathrm{~g} / \mathrm{kg}$ body mass $/$ day for $5-6$ days, followed by a maintenance dose of $0.03 \mathrm{~g} / \mathrm{kg}$ body mass/day to eliminate varied body masses as a confounder. Syrotuik and Bell (2004) examined a relative dosing strategy similar to the recommendation of Hultman et al., (1996) but observed a varied response in increased intramuscular $\mathrm{Cr}$ levels between individuals.

Therefore, the purpose of this study was two-fold and involved determining, in resistance-trained males, the effects of five weeks of resistance training in conjunction with a typical relative $\mathrm{Cr}$ dosing protocol followed by four weeks of resistance training after ceasing $\mathrm{Cr}$ supplementation on: 1) body composition and muscle strength, 2) whole-body $\mathrm{Cr}$ metabolism.

\section{Methods}

\subsection{Participants}

Nineteen apparently healthy, resistance-trained [regular, consistent resistance training (i.e., thrice weekly) for at least one year prior to the study], males between the ages of 18-23 completed the study. Participants were required to perform a leg press 1-RM of at least 2.5 times their body weight followed by at least 10 repetitions at $70 \%$ of their 1RM during a familiarization session to be considered trained to participate (Coburn and Malek, 2012). Participants were recruited from Baylor University and from the area surrounding Waco, TX, USA. Overall, 32 healthy males were recruited. Nine elected to abstain from the study and four elected to withdraw. As a result, 19 participants completed the study. Only participants considered as low risk for cardiovascular disease and with no contraindications to exercise as outlined by the American College of Sports Medicine (ACSM), who had not consumed any nutritional supplements (excluding multi-vitamins) one month prior, and not consumed $\mathrm{Cr}$ in six months prior to the study were allowed to participate. Approval to conduct to study was granted by the Baylor University Institutional Review Board for the Protection of Human Subjects in Research. All experimental procedures involved in the study conformed to the ethical consideration of the Declaration of Helsinki. Individuals interested in the study were interviewed by phone and those believed to meet eligibility criteria were invited to attend an entry/familiarization session. Participants were familiarized to the study protocol by verbal and written explanation and then read and signed a university-approved informed consent document. Potential participants then completed a medical history questionnaire and underwent a general physical examination. Eligible participants were given an appointment time to perform baseline/pre-supplementation assessments and underwent their first testing session within two weeks of familiarization.

\subsection{Design}

In a double-blind procedure, participants were randomly assigned to groups using a random number generator. Supplementation involved orally ingesting packets containing a powdered dextrose placebo [PL (AST Sports Science; Golden, CO, USA)] or Cr monohydrate [CR (AST Sports Science; Golden, CO, USA)]. After baseline testing procedures and lean body mass determination via DEXA, participants in the CR and PL group ingested their respective supplement at a relative daily dose of $0.3 \mathrm{~g} / \mathrm{kg}$ lean body mass $(\approx 17-20 \mathrm{~g} /$ day $)$ for one week in the loading phase and immediately following the loading phase, a relative daily dose of $0.075 \mathrm{~g} / \mathrm{kg}$ lean body mass $(\approx 5-7 \mathrm{~g} /$ day), during the four-week maintenance phase. All groups ceased supplementation on Day 36 following the four-week maintenance phase, which was then followed by a four-week washout phase without supplementation.

For Cr monohydrate and maltodextrose, both supplements were HPLC certified to be $99 \%$ and $98 \%$ pure, as confirmed by the manufacturer. Supplements were ingested with water on an empty stomach at 8:00 am, 12:00 pm, 4:00 pm, and 8:00 pm each day during the loading phase (equal constituent dose). During the maintenance phase, the daily standardized supplement (one packet/day, contained whole daily dose) was ingested at 12:00 pm. Dextrose and $\mathrm{Cr}$ powders were comprised of similar mesh size, texture, taste, and appearance and prepared by an objective third-party company (AST Sport Science, Colorado Springs, CO, USA). Supplement packets for each participant were individually weighed on an analytical balance (Denver Instrument, Golden, CO, USA) to the nearest $1 \%$ of the prescribed dose, and appropriately blinded by a lab technician not involved in the study. Participants were provided with dose packets one week at a time, and required to present empty packets each week to receive the next week's supplement. At Day 22, participants' doses were adjusted based on any changes in lean mass. Compliance to the supplementation protocol was monitored by the return of empty supplement packets each week and verified verbally.

\subsection{Strength Testing}

Participants performed four one-repetition maximum (1-RM) tests on the angled leg press sled (Nebula, Columbus, $\mathrm{OH}$, USA) at Day $0,8,36,64$. Participants warmed-up by completing two sets of $8-10$ repetitions at approximately $50 \%$ of the estimated 1-RM, with two minutes rest in between all sets. Participants completed three to five repetitions at approximately $75 \%$ of the estimated 1-RM. The weight was increased conservatively, and the participant attempted to lift the weight for one repetition. If successful, the participant rested for two minutes before attempting the next weight increment. This was continued until the participant failed to complete the lift (Schwarz et al., 2015). For the 70\% 1-RM evaluation during the familiarization session, participants were allowed to rest five minutes following the determination of their 1-RM. 
2.4 Body Composition Measures and Dietary Recall

Total body mass $(\mathrm{kg})$ was determined on a Detecto digital scale (Webb City, MO, USA). Total body water (extracellular and intracellular) was determined with bioelectrical impedance (Xitron 4200, San Diego, CA, USA). Percent body fat, fat mass, and lean mass (bone mass excluded) were determined using dual-energy X-ray absorptiometer (DEXA; Hologic Discovery, Bedford MA, USA). Body composition was assessed at each of the five testing sessions at Day 0 , $8,22,36$, and 64 .

Participants recorded their dietary intake for 24 hours prior to each of the five testing sessions. The diets were not standardized and participants were instructed not to change their dietary habits during the study. The 24-hour dietary recalls were evaluated with a dietary assessment software program (Food Processor, ESHA Research, Salem OR, USA) to determine the average daily caloric, protein, carbohydrate, and fat intakes for the duration of the study.

\subsection{Resistance Training Protocol}

Participants followed a periodized 4-day/week resistance-training program split into two upper-body and two lowerbody workouts/week, for nine weeks (Table 1). For each exercise, participants performed three sets of 10 repetitions with as much weight as they could lift per set $(\sim 70-80 \%$ of $1 \mathrm{RM})$. If they could lift fewer than 10 repetitions, they were instructed to reduce the weight, and if they could lift more than 10 repetitions at a given weight, they were instructed to increase the weight. Participants rested no longer than three minutes between exercises and no longer than two minutes between sets. During the familiarization session, participants gave verbal confirmation of how to properly perform each exercise.

Table 1. Upper and Lower-Body Workout

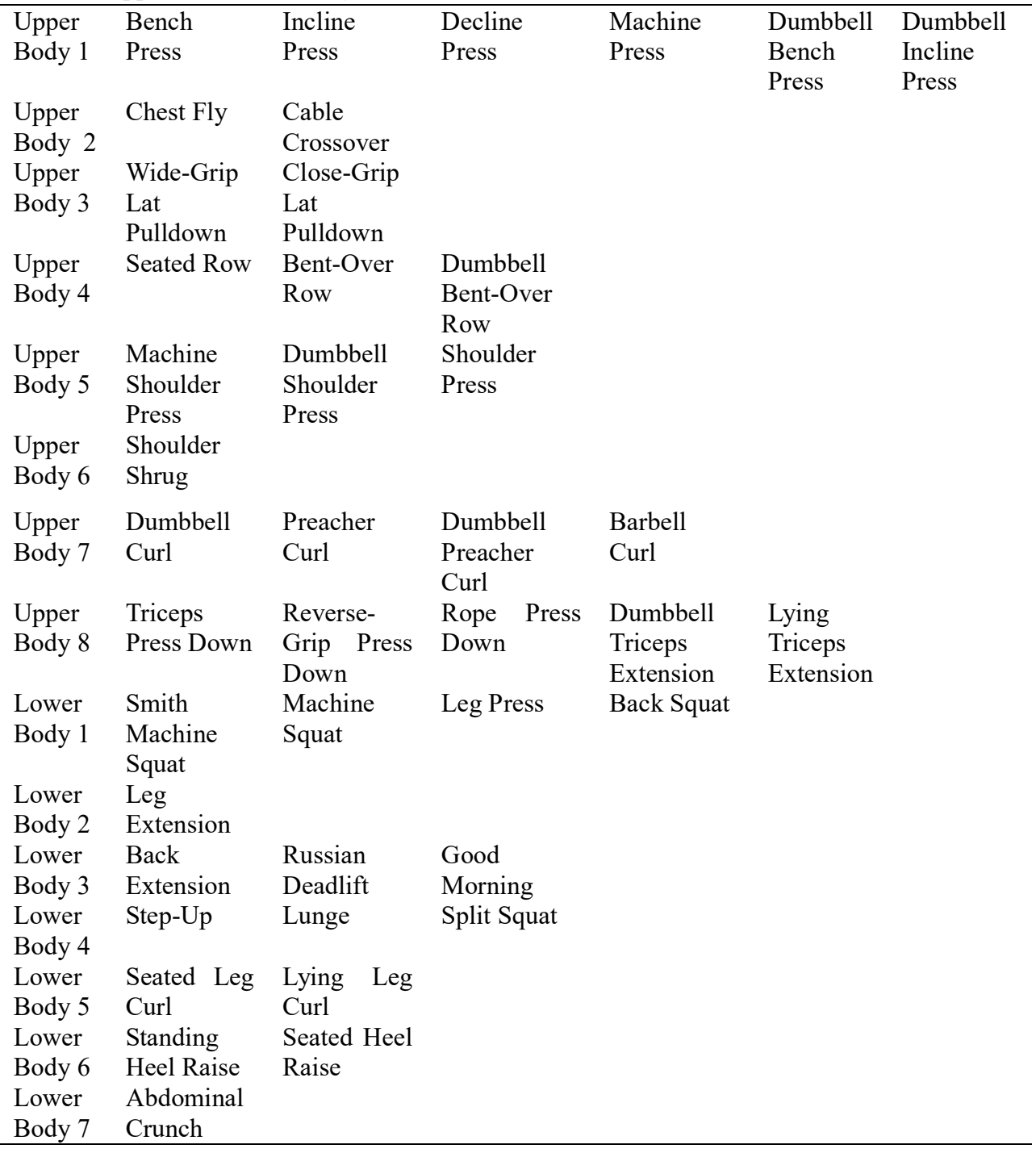

For both upper- and lower-body workouts, the participants were only required to perform the same exercise from a particular group for the current workout, but were allowed to select a different exercise from each group during a subsequent workout at their discretion. Abdominal crunch was performed in sets of 25 repetitions.

2.6 Serum, Urine and Muscle Collection

Participants fasted for eight hours prior to donating blood and urine samples. Venous blood samples were collected from 
the antecubital vein into two $7.5 \mathrm{~mL} \mathrm{SST}$ collection tubes and one $4 \mathrm{~mL}$ EDTA tube using a standard Vacutainer apparatus for serum and whole blood analysis, respectively. Blood samples taken in the serum tubes were allowed stand at room temperature for 15 minutes, centrifuged for 15 minutes at 2,000 rpm, and then the serum was removed and frozen at $-80^{\circ} \mathrm{C}$ for later analysis. A total of six blood samples were obtained: Day 0, 4, 8, 22, 36, and 64 .

Urine samples were obtained in mid-stream into a $50 \mathrm{ml}$ collection tube using a standard collection protocol. Samples were collected on Day $0,4,8,15,22,29,36,50$, and 64 . Urine samples were separated into $1 \mathrm{~mL}$ aliquots and frozen at $-80^{\circ} \mathrm{C}$ for later analysis.

Percutaneous muscle biopsies $(50-70 \mathrm{mg}$ ) were obtained from the middle portion of the vastus lateralis muscle of the dominant leg at the midpoint between the patella and the greater trochanter of the femur at a depth of one $\mathrm{cm}$. For the subsequent four biopsies, tissue extraction occurred approximately in the same location as the initial biopsy by using the pre-biopsy scar, depth markings on the needle, and a successive incision that was made approximately one $\mathrm{cm}$ to the former from medial to lateral. Adipose tissue was trimmed from the muscle tissue and the sample was immediately flash-frozen in liquid nitrogen and subsequently stored at $-80^{\circ} \mathrm{C}$ for later analysis. A total of five muscle samples were collected prior to the first dose of supplement Day 0, 8, 22, 36, and 64.

\subsection{Serum, Urine and Muscle Cr Analysis}

Urine, blood, and muscle tissue samples were analyzed for free $\mathrm{Cr}$ using the diacetyl/ $\alpha$-napthtol reaction (Gundlach et al., 1968).Unmodified urine and serum samples were immediately ready for analysis, while muscle tissue samples required additional preparation. Muscle tissue samples $(\sim 10 \mathrm{mg})$ were dried overnight in a vacuum centrifuge (ThermoSavant Speed Vac, Waltham, MA, USA), then powdered at room temperature with mortar and pestle. Powdered muscle was weighed $(0.5-3.0 \mathrm{mg})$ and then $\mathrm{Cr}$ was extracted in a $0.5 \mathrm{M}$ perchloric acid/1 mM EDTA solution on ice for 15 minutes. The samples were then spun in a $4^{\circ} \mathrm{C}$ centrifuge at $15,000 \mathrm{rpm}$ for 5 minutes, and the supernatant was neutralized with $2.1 \mathrm{M} \mathrm{KHCO}_{3} / 0.3 \mathrm{M}$ MOPS solution, after which the supernatant was prepared for analysis. Total $\mathrm{Cr}$ of muscle samples was determined by reaction with $6.94 \mathrm{mM} \alpha$-napthtol and a 1:2500 dilution of diacetyl. The reaction was incubated for 15 minutes at room temperature in the dark, and color formation was detected at $520 \mathrm{~nm}$ with microplate reader (xMark, Bio-Rad, Hercules, CA, USA). The samples were run against a standard curve of known $\mathrm{Cr}$ concentrations and total muscle $\mathrm{Cr}$ concentrations were expressed relative to muscle dry mass. The coefficient of variation for this assay was $6.7 \%$.

Urine and serum levels of creatinine were determined photometrically by a DADE Dimension RXL clinical chemistry analyzer (Dade-Behring, Inc., Newark, DE, USA). Quality control and calibration procedures were completed prior to all analyses using liquid assay multiqual (BIO-RAD, Hercules, CA, USA). For both assays, the coefficients of variation were less than $5 \%$.

\subsection{Statistical Analysis}

Data were analyzed using univariate two-way repeated measures analysis of variance (ANOVA) with the Statistical Package for Social Sciences (SPSS Inc., Chicago, IL, USA). Comparisons of demographics and supplement intake were determined using an independent Student's t-test. The use of parametric analysis was determined by evaluating kurtosis for each variable. For the analyses of urine, blood, muscle, body composition, and strength, respective $2 \times 9,2$ x 6, 2 × 5, 2 × 5, and $2 \times 4$ repeated measures ANOVAs were utilized. An a-priori power calculation showed that 10 participants per condition was adequate to detect a significant difference between conditions in the marker of muscle strength in response to resistance training, given a type I error rate of 0.05 and a power of 0.80 . Data were considered significantly different when the probability of error was 0.05 or less. Significant within-intensity and within-time differences were determined using Fisher's Least Significant Difference post-hoc test. If within-group assumption of sphericity was violated using Mauchly's Test of Sphericity, the Greenhouse-Geisser correction factor was used to evaluate observed within-group F-ratios to protect against Type I error. When necessary, Cohen's $d$ effect calculations were performed to determine the size and significance between groups, independent of group size.

\section{Results}

\subsection{Demographics}

Nineteen $(C R=9, P L=10)$ completed the study with no significant difference between groups in age [R 20.1 (1.6) vs. PL 20.1 (1.1) years; $p=0.76$ ] or baseline body fat percentage [CR 17.6 (8.8) vs. PL 17.0 (9.1); $p=0.13$ ], but there was a significant difference between groups in height [CR 181.3 (6.4) vs. PL $174.4(5.8) \mathrm{cm} ; \mathrm{p}=0.03$ ].

In regard to compliance, $\mathrm{CR}$ and PL were $95.23 \pm 9.36 \%$ and $93.74 \pm 8.82 \%$ compliant to the resistance training program, respectively. For supplementation, CR and PL were $96.21 \pm 4.87 \%$ and $94.69 \pm 3.98 \%$ compliant, respectively, to the supplementation protocol.

\subsection{Body Composition Measures}

Body composition measures are presented in Table 2. There was a group $\mathrm{x}$ time interaction for increases in total body mass Day 1 and $64(\mathrm{p}=0.03)$ and lean mass at Day 1 and $64(\mathrm{p}=0.01)$. There were no significant differences found between groups for total body water $(p=0.99)$, intracellular fluid $(p=0.44)$, extracellular fluid $(p=0.69)$, extracellular: intracellular ratio $(\mathrm{p}=0.80)$, or extracellular: total body water ratio $(\mathrm{p}=0.76)$.

\subsection{Strength Measures and Dietary Intake}

Strength measures are presented in Table 2 and dietary intake is presented in Table 3. There was a significant main 
effect for leg press 1-RM to increase with time at Day 8, 36, and $64(\mathrm{p}=0.001)$; however, there was no significant group $\mathrm{x}$ time interaction $(\mathrm{p}=0.17)$. The overall average strength gain for both groups as determined by change in leg press 1 -RM over the course of the study was $33.01 \pm 23.29 \mathrm{~kg}$. The strength gain for the CR group was $41.16 \pm 26.90$ $\mathrm{kg}$ compared to the PL group, which was $25.68 \pm 17.77 \mathrm{~kg}$. There was not a significant difference within or between groups in caloric intake $(\mathrm{p}=0.45)$, protein $(\mathrm{p}=0.61)$, carbohydrate $(\mathrm{p}=0.63)$, or fat $(\mathrm{p}=0.26)$ over the course of the study.

\subsection{Urine, Serum, and Muscle Cr}

There was no statistical difference observed in serum Crn $(\mathrm{p}=0.14)$ nor urine $\operatorname{Crn}(\mathrm{p}=0.15)$ (Table 4), but a significant group $\mathrm{x}$ time interaction for increased serum $\mathrm{Cr}$ in the $\mathrm{CR}$ group observed at Day 4, 8, $22 \quad(\mathrm{p}=0.003)($ Table 5). However, a significant group $\mathrm{x}$ time interaction for increased urine $\mathrm{Cr}$ at Day 4, 8, 15, 22, 29, and $36(\mathrm{p}=0.01)$ in the $\mathrm{CR}$ group was located. For total muscle $\mathrm{Cr}$ (Table 6), a significant group x time interaction for total muscle Cr existed demonstrating the CR group to be significantly increased at Day $8(\mathrm{p}=0.001), 22(\mathrm{p}=0.003)$, and $36(\mathrm{p}=0.001)$.

\section{Discussion}

\subsection{Strength Measures and Dietary Intake}

The purpose of this study was to examine the effects of a relatively-dosed $\mathrm{Cr}$ monohydrate supplementation protocol on body composition, muscle strength, and whole-body $\mathrm{Cr}$ metabolism in resistance-trained males. Even though $\mathrm{Cr}$ supplementation significantly increased muscle $\mathrm{Cr}$ concentration, the current investigation failed to find any significant Cr-induced improvements in body composition and muscle strength.

Table 2. Body composition and 1-RM Leg Press for the placebo (PL) and creatine (CR) groups

\begin{tabular}{llll}
\hline Variable & Session & CR & PL \\
\hline Total Body Mass $(\mathrm{kg})$ & Day 1 & $83.5(19.8) *$ & $77.9(14.7) *$ \\
& Day 8 & $84.4(19.5)$ & $77.6(14.8)$ \\
& Day 22 & $85.0(19.5)$ & $78.3(14.6)$ \\
& Day 36 & $84.8(18.9)$ & $77.5(14.6)$ \\
& Day 64 & $84.6(19.4) *$ & $77.8(15.0) *$ \\
Lean Body Mass $(\mathrm{kg})$ & Day 1 & $62.7(6.8) *$ & $59.3(7.0)^{*}$ \\
& Day 8 & $63.3(6.4)$ & $59.1(6.8)$ \\
& Day 22 & $63.8(6.5)$ & $59.7(7.1)$ \\
& Day 36 & $63.9(6.3)$ & $58.9(6.9)$ \\
& Day 64 & $63.5(6.2) *$ & $58.8(6.8) *$ \\
& Day 1 & $342.9(84.0)$ & $347.7(134.1)$ \\
& Day 8 & $375.3(105.5) \dagger$ & $359.1(152.1) \dagger$ \\
& Day 36 & $379.8(91.2) \dagger$ & $366.1(139.5) \dagger$ \\
& Day 64 & $384.1(101.9) \dagger$ & $373.4(146.0) \dagger$ \\
& Day 1 & $0.534(0.078)$ & $0.550(0.04)$ \\
& Day 8 & $0.550(0.081)$ & $0.542(0.042)$ \\
& Day 22 & $0.543(0.080)$ & $0.543(0.034)$ \\
& Day 36 & $0.551(0.077)$ & $0.540(0.044)$ \\
& Day 64 & $0.542(0.083)$ & $0.545(0.037)$ \\
\hline
\end{tabular}

Data are expressed as means $( \pm \mathrm{SD}) . *$ denotes a significant group $\mathrm{x}$ time interaction for increases in total body mass $(\mathrm{p}$ $=0.03)$ and lean mass $(\mathrm{p}=0.01)$ at Day 1 and 64. There were no significant differences relative in total body water $(\mathrm{p}=$ $0.99)$. $\dagger$ denotes a significant main effect in both groups for leg press 1-RM to increase with time at Day 8, 36, and 64 (p $=0.001)$; however, there was no significant group $\mathrm{x}$ time interaction $(\mathrm{p}=0.17)$.

There was a significant increase over time with resistance training in muscular strength for both groups. This strength increase in both groups was expected (Rawson and Volek, 2003); however, Cr supplementation failed to confer an additional strength increase beyond the PL group (Table 2). Statistical analysis revealed a moderate effect size for the increase in leg press $1-\mathrm{RM}$ in the CR group $(\mathrm{d}=0.51)$. This suggests additional participants might have provided adequate statistical power to reveal a significantly greater strength gain in the CR group, which is in agreement with previous research (Earnest et al., 1995; Souza-Junior et al., 2011; Rawson and Volek, 2003). The participants were instructed to maintain their normal mixed diets for the duration of the study, and there were no significant differences between- or within-groups throughout the course of the study for daily total caloric intake (Table 3). Therefore, it is unlikely that dietary intake influenced the strength measures. It is feasible some participants did not comply fully with the resistance training protocol, despite indicating otherwise, or incorrectly reported weights lifted, potentially introducing inaccuracies. 


\begin{tabular}{cccc}
\multicolumn{4}{l}{ Table 3. Dietary intake for the placebo (PL) and creatine (CR) groups } \\
\hline Variable & Session & CR & PL \\
\hline Calories $(\mathrm{kcal} / \mathrm{kg})$ & Day 1 & $34.8(11.5)$ & $36.7(21.5)$ \\
& Day 8 & $26.8(10.0$ & $28.7(11.6)$ \\
& Day 22 & $25.2(7.2)$ & $28.3(10.3)$ \\
& Day 36 & $20.3(8.2)$ & $27.1(9.0)$ \\
& Day 64 & $19.7(12.1)$ & $35.0(13.7)$ \\
Protein $(\mathrm{g} / \mathrm{kg})$ & Day 1 & $1.39(0.67)$ & $1.69(0.93)$ \\
& Day 8 & $1.26(0.29)$ & $1.13(0.52)$ \\
& Day 22 & $1.16(0.37)$ & $1.15(0.38)$ \\
& Day 36 & $1.00(0.24)$ & $1.12(0.31)$ \\
& Day 64 & $0.92(0.56)$ & $1.10(0.43)$ \\
Carbohydrate $(\mathrm{g} / \mathrm{kg})$ & Day 1 & $3.92(1.78)$ & $3.78(2.15)$ \\
& Day 8 & $2.49(1.46)$ & $3.41(1.94)$ \\
& Day 22 & $2.53(0.60)$ & $3.25(1.45)$ \\
& Day 36 & $2.27(1.02)$ & $3.10(1.60)$ \\
& Day 64 & $2.19(1.49$ & $3.86(1.75)$ \\
Dietary Fat $(\mathrm{g} / \mathrm{kg})$ & Day 1 & $1.52(0.76)$ & $1.62(1.30)$ \\
& Day 8 & $1.31(0.59)$ & $1.22(0.48)$ \\
& Day 22 & $1.18(0.51)$ & $1.18(0.40)$ \\
& Day 36 & $0.81(0.51)$ & $1.14(0.35)$ \\
& Day 64 & $0.70(0.63)$ & $1.76(0.75)$ \\
\hline & & & \\
\hline & &
\end{tabular}

Data are expressed as means $( \pm \mathrm{SD})$. No significant differences for any of the dietary variables existed within or between groups $(\mathrm{p}>.05)$.

Previous studies have indicated similar consumption of $\mathrm{Cr}$ combined with resistance exercise significantly improves body composition and fat-free mass (Greenhaff, 1995; Rawson and Volek, 2003). The results of the current investigation for total body mass and lean mass, both of which were significantly elevated in the CR group, were in agreement with prior research (Willoughby and Rosene, 2001). A significant change in percent body fat was detected; however, a low to moderate effect size for a decrease in percent body fat in the CR group was observed $(d=0.33)$. There was a significant increase in intracellular fluid and total body water in the CR group, while there was no significant change in intracellular and extracellular water, or the ratio between the two. $\mathrm{Cr}$ is an osmotically active compound, such that increases in total body $\mathrm{Cr}$ retention caused by supplementation should consequently produce an increase in water retention. Although, it should be noted that a loading phase of $25 \mathrm{~g} / \mathrm{d}$ for 7 days followed by a maintenance phase of $5 \mathrm{~g} / \mathrm{d}$ for 21 days resulted in increases in intramuscular $\mathrm{Cr}$ and total body water, without altering proportional fluid distribution (Powers et al., 2003). In the current investigation when total body water was expressed relative to total body mass, the significant increase was not present. These findings are consistent with the previous study (Powers et al., 2003), which found that similar Cr loading and maintenance increased total body water without altering overall fluid distribution.

The $\mathrm{Cr}$ supplementation was similar to previous studies demonstrating increases in serum and muscle $\mathrm{Cr}$ in response to Cr supplementation (Burke et al., 2003; Casey et al., 1996; Greenhaff et al., 1994; Hultman et al., 1996; Snow et al., 1998). In the present study, the CR group consumed an average $18.8 \mathrm{~g}$ /day for a loading phase, followed by a maintenance phase of $4.77 \mathrm{~g} /$ day. Interestingly these doses are approximately the same as absolute doses of $20 \mathrm{~g} /$ day for loading and $5 \mathrm{~g}$ /day maintenance phases (Greenhaff et al., 1994; Preen et al., 2003). Snow et al. (1998) provided a bolus dose of $30 \mathrm{~g}$ of $\mathrm{Cr}$ for only 5 days showing elevated total muscle $\mathrm{Cr}$, but failed to observe an improvement in 20 -second cycle ergometer sprints. The current investigation observed similar increases in total muscle $\mathrm{Cr}$ despite utilizing a relative dose based on lean mass. However, unlike much of the previous research the current study examined intramuscular $\mathrm{Cr}$ during a four-week post-supplementation washout phase. Intramuscular $\mathrm{Cr}$ levels returned to near baseline levels at the end of the washout phase. The present data suggest that, in resistance-trained males, chronic supplementation of $\mathrm{Cr}$ at the dose provided (relative to kilogram of lean mass) during five weeks of resistance training is capable of increasing and subsequently maintaining elevations in muscle $\mathrm{Cr}$.

\subsection{Urine $\mathrm{Cr}$ and $\mathrm{Crn}$}

In prior investigations, a loading dosage of $0.1 \mathrm{~g} \mathrm{Cr} / \mathrm{kg}$ fat-free mass/day resulted in $46 \% \mathrm{of} \mathrm{Cr}$ ingested being excreted in the urine 24 hours post-supplementation, but no changes in Crn excretion (Burke et al., 2001; Greenhaff et al., 1994; Preen et al., 2003). Comparatively in the current investigation, approximately three times that amount of $\mathrm{Cr}$ was ingested by our participants during the loading phase, and after three days of supplementation, urine $\mathrm{Cr}$ concentrations increased over 1000-fold from baseline levels, and remained similarly elevated after one week of supplementation (Table 4). As a result, a significant increase in urinary $\mathrm{Cr}$ was observed; however, there was no significant increase in 
urinary $\mathrm{Crn}$. These findings are consistent with previous studies showing increases in urinary $\mathrm{Cr}$ but not in urinary $\mathrm{Crn}$ (Powers et al., 2003; Syrotuik and Bell, 2004). This suggests the supplementation dose of $\mathrm{Cr}$ was higher than the functional capacity to be metabolized, and was wasted via urinary excretion. Despite the supplementation dose based on lean mass measures to attempt to reduce this occurrence, considerable amounts of $\mathrm{Cr}$ were still essentially wasted.

Table 4. Urine $\mathrm{Cr}$ and Crn values for the placebo (PL) and creatine (CR) groups

\begin{tabular}{lllll}
\hline & Urine $\operatorname{Cr}(\mu \mathrm{M})$ & & \multicolumn{2}{l}{ Urine Crn $(\mathrm{mg} / \mathrm{dL})$} \\
\hline & $\mathrm{CR}$ & $\mathrm{PL}$ & $\mathrm{CR}$ & $\mathrm{PL}$ \\
Day 0 & $249(73)$ & $473(719)$ & $135(62)$ & $118(75)$ \\
Day 4 & $27833(5933) *$ & $209(132)$ & $157(62)$ & $89(68)$ \\
Day 8 & $23716(11168) *$ & $197(107)$ & $150(129)$ & $96(68)$ \\
Day 15 & $4521(2302) *$ & $152(64)$ & $338(218)$ & $83(33)$ \\
Day 22 & $5529(3410) *$ & $202(118)$ & $135(41)$ & $94(55)$ \\
Day 29 & $4751(4722) *$ & $238(160)$ & $180(74)$ & $148(115)$ \\
Day 36 & $8214(6524) *$ & $225(141)$ & $164(54)$ & $104(66)$ \\
Day 50 & $648(607)$ & $213(95)$ & $193(65)$ & $118(63)$ \\
Day 64 & $531(567)$ & $260(112)$ & $161(69)$ & $144(76)$ \\
\hline
\end{tabular}

Data are expressed as means $( \pm \mathrm{SD}) .{ }^{*}$ denotes a significant group $\mathrm{x}$ time interaction $(\mathrm{p}=0.01)$ for urine $\mathrm{Cr}$ existed in the CR group at Day 4, 8, 15, 22, 29, and 36.

\subsection{Serum and Muscle Cr and Crn}

Serum $\mathrm{Cr}$ concentrations were significantly elevated from baseline after three and seven days of Cr supplementation, and at the end of the maintenance phase (Table 5). A significant elevation in serum Cr was observed in the CR group. Conversely, there was no significant increase in serum Crn. Consistent with previous research (Robinson et al., 2000; Schedel et al., 1999), these findings provide an indication that exogenous $\mathrm{Cr}$ supplementation effectively increased $\mathrm{Cr}$ concentration within the circulation, thereby augmenting the $\mathrm{Cr}$ pool that was available to the skeletal muscle for uptake. Combined with the intramuscular total $\mathrm{Cr}$ data (Table 6), it can be postulated the exogenous $\mathrm{Cr}$ supplementation apparently saturated intramuscular $\mathrm{Cr}$ stores given the high levels of serum and urinary $\mathrm{Cr}$. Furthermore, the overall $\mathrm{Cr}$ supplementation dose could be lowered given the high levels of urinary Cr. An investigation at lower relative supplementation doses of $\mathrm{Cr}$ in resistance-trained males could further clarify the dose response to elicit elevated intramuscular $\mathrm{Cr}$ stores with minimal excretion of $\mathrm{Cr}$. The current investigation observed an average increase in total muscle $\mathrm{Cr}$ of $\sim 30 \mathrm{mmol} / \mathrm{kg}$ dry weights in the CR group. Further examination of the individual data showed 10/11 participants would be classified as responders (Greenhaff et al., 1994). That individual observed an increase of only 18 $\mathrm{mmol} / \mathrm{kg}$ dry weight and thus would be considered a quasi-responder. Combined with the strength data, this suggests additional criteria to be classified as a true responder as opposed to simply total muscle Cr. Although not examined in the current investigation, individuals with a higher percentage of type II fibers have been suggested as an additional factor to an individual's responder status (Lemon, 2002).

Table 5. Serum Crn and Cr values for the placebo (PL) and creatine (CR) groups

\begin{tabular}{lllll}
\hline \multicolumn{4}{c}{ Serum Crn $(\mathrm{mg} / \mathrm{dL})$} & \multicolumn{3}{l}{ Serum $\mathrm{Cr}(\mu \mathrm{M})$} & \\
\hline & CR & PL & CR & PL \\
Day 0 & $0.926(.17)$ & $1.04(.13)$ & $480.6(41.8)$ & $434.7(142.5)$ \\
Day 4 & $1.25(.86)$ & $1.08(.12)$ & $557.7(114.1) *$ & $375.9(71.1)$ \\
Day 8 & $1.12(.17)$ & $1.04(.16)$ & $644.4(185.4) *$ & $417.7(88.9)$ \\
Day 22 & $1.11(.13)$ & $1.08(.13)$ & $517.7(111.4) *$ & $415.3(91.6)$ \\
Day 36 & $1.15(.15)$ & $1.10(.14)$ & $473.4(66.7)$ & $407.1(105)$ \\
Day 64 & $1.13(.13)$ & $1.07(.16)$ & $454.1(77.9)$ & $383.2(73.5)$ \\
\hline
\end{tabular}

Data are expressed as means $( \pm \mathrm{SD}) .{ }^{*}$ denotes a significant group $\mathrm{x}$ time interaction $(\mathrm{p}=0.03)$ for increased serum $\mathrm{Cr}$ in the CR group at Day 4, 8, 22. No statistical difference was observed in serum Crn $(\mathrm{p}=0.14)$.

Table 6. Skeletal muscle measures of $\mathrm{Cr}$ values for the placebo (PL) and creatine (CR) groups.

\begin{tabular}{lll}
\hline \multicolumn{2}{l}{ Total Muscle Cr (mmol/kg dry wt) } \\
\hline CR & PL \\
Day 0 & $112.1(12)$ & $109.8(17.2)$ \\
Day 8 & $143.3(10.6)^{*}$ & $114.3(14.4)^{*}$ \\
Day 22 & $138(9.7)^{*}$ & $116.8(11.1)^{*}$ \\
Day 36 & $136.1(7.1)^{*}$ & $115.0(11)^{*}$ \\
Day 64 & $110.3(11.9)$ & $108.3(8.2)$ \\
\hline
\end{tabular}

Data are expressed as means $( \pm \mathrm{SD})$. ${ }^{*}$ denotes a significant group $\mathrm{x}$ time interaction $(\mathrm{p}=0.003)$ for total muscle Cr concentration existed in the CR group at Day 8, 22, and 36. 


\section{Conclusion and Practical Applications}

A relative supplementation dose of $\mathrm{Cr}$ should be utilized to maximize ergogenic benefits while minimizing excretion of extra $\mathrm{Cr}$. Although, additional investigations should examine lower relative doses than $0.3 \mathrm{~g} / \mathrm{kg}$ lean mass followed by four weeks 0.075 used in the current design to determine precise dosing strategies to maximize ergogenic benefits with minimal excretion or waste of $\mathrm{Cr}$ through urine. There are several limitations including the sample size was relatively small, but larger than in many published studies with a similar experimental design. The daily consumption of the supplement and weight training sessions were not directly monitored. Finally, it was assumed participants were truthful about their compliance with the resistance training and supplementation protocols and in not ingesting any additional nutritional supplements during the study. One week of $\mathrm{Cr}$ supplementation at $0.3 \mathrm{~g} / \mathrm{kg}$ lean mass followed by four weeks $0.075 \mathrm{~g} / \mathrm{kg}$ lean mass successfully elicited significant gains in total muscle $\mathrm{Cr}$ content, total body mass, lean mass, and total body water. Although resistance training increased muscle strength in both groups, Cr supplementation did not have an additive effect. Supplementation significantly elevated serum $\mathrm{Cr}$ levels and $\mathrm{Cr}$ excretion in the urine, indicating adaptive handling of exogenous $\mathrm{Cr}$. The saturation of intramuscular $\mathrm{Cr}$ in combination with the serum and urine $\mathrm{Cr}$ data suggests that, in resistance-trained men, even an individualized, relatively-dosed $\mathrm{Cr}$ supplementation protocol creates high levels of $\mathrm{Cr}$ being excreted during the loading and maintenance phases.

\section{References}

Bessman, S.P., Carpenter, C.L. (1985). The creatine-creatine phosphate energy shuttle. Annual Review Biochemistry, 54, $831-862$.

Burke, D.G., Chilibeck, P.D., Parise, G., Candow, D.G., Mahoney, D., Tarnopolsky, M. (2003). Effect of creatine and weight training on muscle creatine and performance in vegetarians. Medicine \& Science in Sports \& Exercise, 35, 1946-1955.

Burke, D.G., Smith-Palmer, T., Holt, L.E., Head, B., Chilibeck, P.D. (2001). The effect of 7 days of creatine supplementation on 24-hour urinary creatine excretion. Journal of Strength \& Conditioning Research, 15, 59-62.

Casey, A., Constantin-Teodosiu, D., Howell, S., Hultman, E., Greenhaff, P.L. (1996). Creatine ingestion favorably affects performance and muscle metabolism during maximal exercise in humans. American Journal of Physiology. 271, $31-37$.

Coburn, J.W., Malek, M.H. (2012). NSCA's Essentials of Personal Training-2nd Edition. Champaign, IL: Human Kinetics.

Cooper, R., Naclerio, F., Allgrove, J., Jimenez, A. (2012). Creatine supplementation with specific view to exercise/sports performance: an update. Journal of the International Society Sports Nutrition, 9, 33.

Earnest, C.P., Snell, P.G., Rodriguez, R., Almada, A.L., Mitchell, T.L. (1995). The effect of creatine monohydrate ingestion on anaerobic power indices, muscular strength and body composition. Acta Physiologic Scandinavia, 153, 207-209.

Greenhaff, P.L. (1995). Creatine and its application as an ergogenic aid. International Journal of Sport Nutrition, 5 , $100-110$.

Greenhaff, P.L., Bodin, K., Soderlund, K., Hultman, E. (1994). Effect of oral creatine supplementation on skeletal muscle phosphocreatine resynthesis. American Journal of Physiology, 266, 725-730.

Gundlach, G., Hoppe-Seyler, G.F., Johann, H. (1968). Automatic determination of creatine using the diacetyl reaction. Journal of Clinical Chemistry and Clinical Biochemistry, 6, 415-418.

Häkkinen, K., Pakarinen, A., Kraemer, W.J., Häkkinen, A., Valkeinen, H., Alen, M. (2001). Selective muscle hypertrophy, changes in EMG and force, and serum hormones during strength training in older women. Journal of Applied Physiology, 91, 569-580.

Hultman, E., Söderlund, K., Timmons, J.A., Cederblad, G., Greenhaff, P.L. (1996). Muscle creatine loading in men. Journal of Applied Physiology, 81, 232-237.

Lanhers, C., Pereira, B., Naughton, G., Trousselard, M., Lesage, F.X., Dutheil, F. (2015). Creatine Supplementation and Lower Limb Strength Performance: A Systematic Review and Meta-Analyses. Sports Medicine Auckland New Zeeland, 45, 1285-1294.

Lemon, P.R. (2002). Dietary creatine supplementation and exercise performance: why inconsistent results? Canadian Journal of Applied Physiology Review, 27, 663-681.

Powers, M.E., Arnold, B.L., Weltman, A.L., Perrin, D.H., Mistry, D., Kahler, D.M., Kraemer, W., Volek, J. (2003). Creatine Supplementation Increases Total Body Water Without Altering Fluid Distribution. Journal of Athletic Training, $38,44-50$.

Preen, D., Dawson, B., Goodman, C., Beilby, J., Ching, S. (2003). Creatine supplementation: a comparison of loading and maintenance protocols on creatine uptake by human skeletal muscle. International Journal of Sport Nutrition Exercise Metabolism,13, 97-111.

Rawson, E.S., Volek, J.S. (2003). Effects of creatine supplementation and resistance training on muscle strength and weightlifting performance. Journal of Strength \& Conditioning Research, 17, 822-831. 
Robinson, T.M., Sewell, D.A., Casey, A., Steenge, G., Greenhaff, P.L. (2000). Dietary creatine supplementation does not affect some haematological indices, or indices of muscle damage and hepatic and renal function. British Journal of Sports Medicine, 34, 284-288.

Schedel, J.M., Tanaka, H., Kiyonaga, A., Shindo, M., Schutz, Y. (1999). Acute creatine ingestion in human: consequences on serum creatine and creatinine concentrations. Life Science, 65, 2463-2470.

Schwarz, N.A., Spillane, M.B., McKinley, S.K., Andre, T.L., Gann, J.J., Willoughby, D.S. (2015) Acute Myosin Heavy Chain Isoform mRNA Expression in Response to Two Resistance Exercise Intensities With Equal Volume Load in Resistance-Trained Men. Journal of Strength \& Conditioning Research, 29, 2326-2332.

Snow, R.J., McKenna, M.J., Selig, S.E., Kemp, J., Stathis, C.G., Zhao, S. (1998). Effect of creatine supplementation on sprint exercise performance and muscle metabolism. American Journal of Physiology, 84, 1667-1673.

Souza-Junior, T.P., Willardson, J.M., Bloomer, R., Leite, R.D., Fleck, S.J., Oliveira, P.R., Simão, R. (2011). Strength and hypertrophy responses to constant and decreasing rest intervals in trained men using creatine supplementation. Journal of the International Society of Sports Nutrition, 8, 17.

Syrotuik, D.G., Bell, G.J. (2004). Acute creatine monohydrate supplementation: a descriptive physiological profile of responders vs. nonresponders. Journal of Strength \& Conditioning Research, 18, 610-617.

Watt, K.O., Garnham, A.P., Snow, R.J. (2004). Skeletal muscle total creatine content and creatine transporter gene expression in vegetarians prior to and following creatine supplementation. International Journal of Sport Nutrition Exercise Metabolism, 14, 517-531.

Willoughby, D.S., Rosene, J. (2001). Effects of oral creatine and resistance training on myosin heavy chain expression. Medicine \& Science in Sports \& Exercise, 33, 1674-1681. 